\title{
Correction to: The impact of external academic accreditation of undergraduate medical program on students' satisfaction
}

Ayman Al-Eyadhy ${ }^{1,3}$ and Shuliweeh Alenezi ${ }^{2,3^{*}}$

Correction to: BMC Medical Education (2021) 21:565

https://doi.org/10.1186/s12909-021-03003-0

Following publication of the original article [1], we have been informed that author Shuliweeh Alenezi should be affiliated as follows:

Department of Psychiatry, College of Medicine, King Saud University, Riyadh, Saudi Arabia.

Vice-Deanship of Quality and Development, College of Medicine, King Saud University, Riyadh, Saudi Arabia.

The original article has been corrected.

\section{Author details}

'Department of Pediatrics, College of Medicine, King Saud University, Riyadh, Saudi Arabia. ${ }^{2}$ Department of Psychiatry, College of Medicine, King Saud University, Riyadh, Saudi Arabia. ${ }^{3}$ Vice-Deanship of Quality and Development, College of Medicine, King Saud University, Riyadh, Saudi Arabia.

Published online: 28 January 2022

\section{Reference}

1. Al-Eyadhy $\mathrm{A}$, Alenezi S. The impact of external academic accreditation of undergraduate medical program on students'satisfaction. BMC Med Educ. 2021;21:565. https://doi.org/10.1186/s12909-021-03003-0.

The original article can be found online at https://doi.org/10.1186/s12909021-03003-0.

*Correspondence: salenizi@ksu.edu.sa

${ }^{2}$ Department of Psychiatry, College of Medicine, King Saud University, Riyadh, Saudi Arabia

${ }^{3}$ Vice-Deanship of Quality and Development, College of Medicine, King

Saud University, Riyadh, Saudi Arabia

Full list of author information is available at the end of the article 